\title{
Seismic analyses of the Messina Bridge project
}

\author{
S. Hernández, L. E. Romera, A. Baldomir \& F. Bravo \\ School of Civil Engineering, University of Coruña, Spain
}

\begin{abstract}
In this paper several preliminary works developed to determine the seismic response of the Messina Bridge project are presented. Firstly the different types of non-linear structural models developed are shown, including global models for the macro-level static and dynamic analysis, and local models for the micro-level analysis. Then, the analyses and several results obtained for static and nonlinear seismic time histories analyses are explained. Finally, the results of the Messina local tower model with a longitudinal push-over analysis are presented.
\end{abstract}

\section{Introduction}

The suspension bridge over the strait of Messina (figure 1) will link Sicily and Calabria with the world longest center span of $3.300 \mathrm{~m}$. The preliminary design used as the basis of the analysis that appear in this article, was developed by Chodai Co., Ltd. in 2004, following the analysis and design specifications for the bridge (ref.TSA002) developed by the concessionaire Stretto Di Messina S.p.A which carries out the research, design, construction and operation of the bridge.

Figure 2 shows the transversal bridge section and one of the towers. The bridge section has three principal girders, one central for two railways and two laterals for road traffic. These girders are connected with transversal girders spaced $30 \mathrm{~m}$. in the longitudinal direction, and suspended at its ends from hangers that connect them with the main cables. The main cables are connected to the ground at the splay saddle in the anchorage, and to the tower saddle at the towers. Figure 3 shows a realistic visualization detail of these girders.

The towers as well as the girders and the suspension system were executed in structural steel of qualities between S355J0 and S420J0. Each tower has an approximate height of $382 \mathrm{~m}$, with a self-weight greater than $5 \times 10^{5} \mathrm{kN}$, and is composed of two inclined columns connected by four transversal girders. 


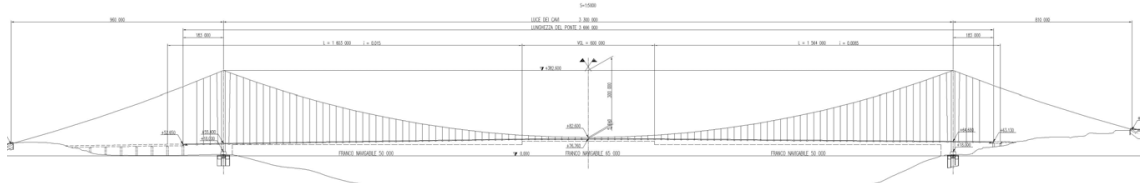

Figure 1: $\quad$ Front and top view of Messina Bridge.

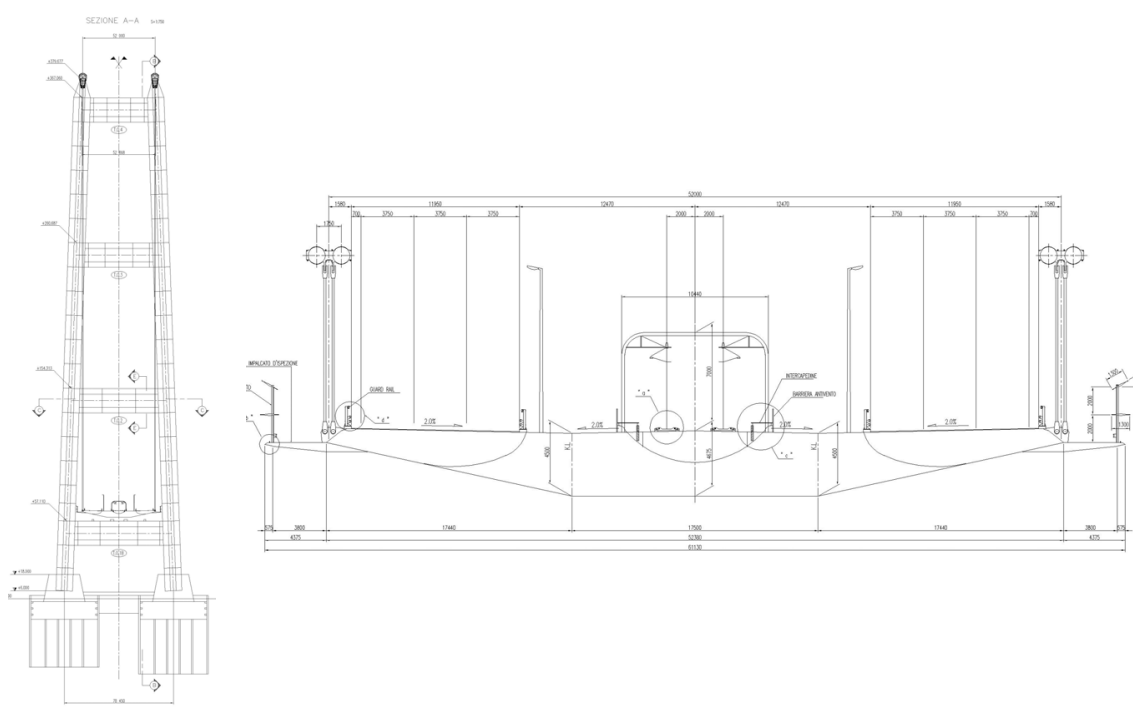

Figure 2: $\quad$ Messina tower and bridge central cross-section.
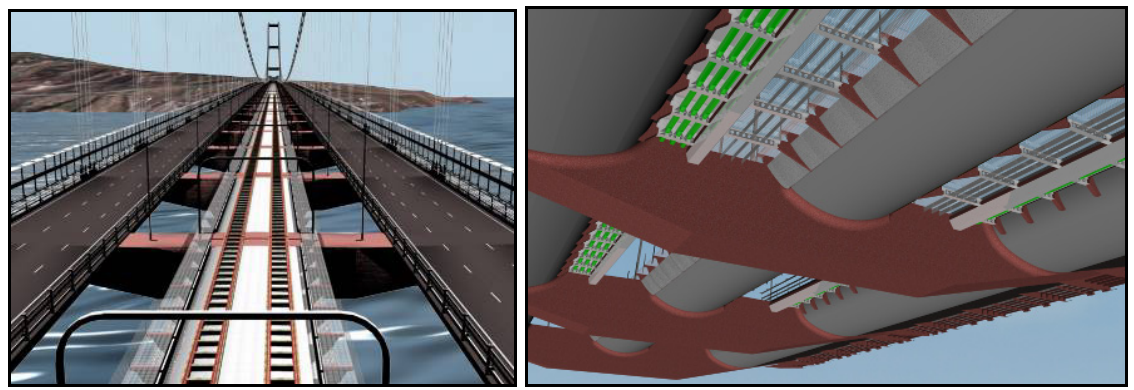

Figure 3: Visualization model: top and bottom aerial views.

The loads considered in design specifications are:

- Dead loads: permanent loads (PP) and non-structural loads (PN)

- Live loads: variable man-generated actions $(\mathrm{Q})$ due to road and railway loads, for local resistance and deformations checks at micro-level (QL), at macrolevel (QA), and for runnability (QR); and variable environmental actions $\mathrm{V}$ due to wind action (VV), seismic action (VS) and thermal actions (VT) 
- Imperfections: fundamentally levels of verticality and rectilinearity errors for the shafts of the towers

- Accidental loads (A)

These loads and their combinations are specified in four limit states:

- SLS1: Limit service state with road and railway runnability and no damage.

- SLS2: Limit service state with only railway runnability and minimal damage.

- SLU: Ultimate limit state with lack of functionality in road and railway, and reparable damage.

- SLIS: Limit state of structural integrity with significant damage.

Due to the great dimensions of the bridge, the static and aero-elastic wind loads are some of the fundamental conditions in the design of the bridge, determining the principal girder geometry. On the other hand the bridge location is one of the most important areas of seismic activity in Europe. The Messina earthquake in 1908 was the deadliest quake in European history, with a magnitude equalled to 7.5 in Ritcher scale and with one return period characterized between 1000/1500 years, caused more than 100000 deaths. The earthquake and the later tsunami destroyed the city of Messina. Therefore, seismic loads are very high and they determine the design of the bridge towers besides the wind loads.

\section{Structural models}

To carry out the static and dynamic analysis one global model of the complete bridge and several local models (of parts) of the bridge were developed, using the commercial finite element programs Cosmos/m v.2.9 [1] and Abaqus v.6 [2].

Figure 4 shows the global model developed using 3-dimensional beam and truss elements to model longitudinal and transversal girders, towers, hangers, main cables and main cable anchorages; linear springs in connections at base tower representing foundation and soil stiffness, and several coupling conditions between degrees of freedom of the girders and the connection system to the towers are applied to ensure the correct behaviour of the connection system. The model has 2848 nodes and 3848 elements and represents initially the bridge under full dead load, with initial stresses due to this load in the main suspension cables, hangers and towers, and the design geometrical configuration, with null shear force at the tower tops.

The global model allows us to develop static and dynamic nonlinear analysis considering the fully nonlinear geometrical behaviour $[3,4]$ due to the geometrical stiffness, the linear stiffness and the contributions by changes in the geometrical configuration. The first step is always an equilibrium iteration check between the complete set of dead loads and the initial stresses, giving a result of zero displacements. To calculate the distribution of initial stresses in equilibrium with dead loads, an iterative program was developed to determine the initial length and geometrical configuration of the main suspension cables with null initial stress, which gives the design configuration under dead loads. 

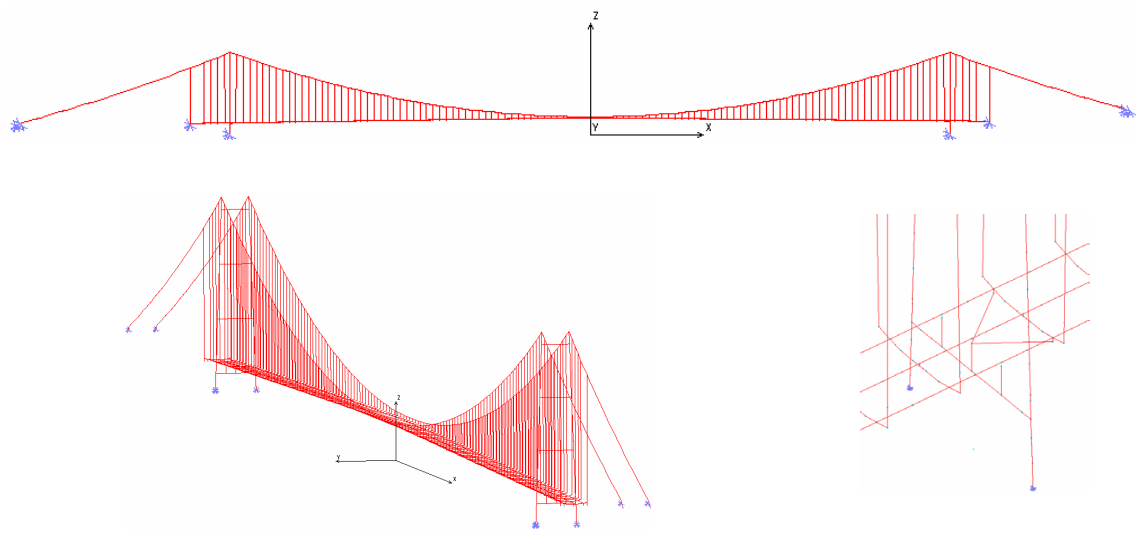

Figure 4: Views of global model and detail of connections between girders and towers.

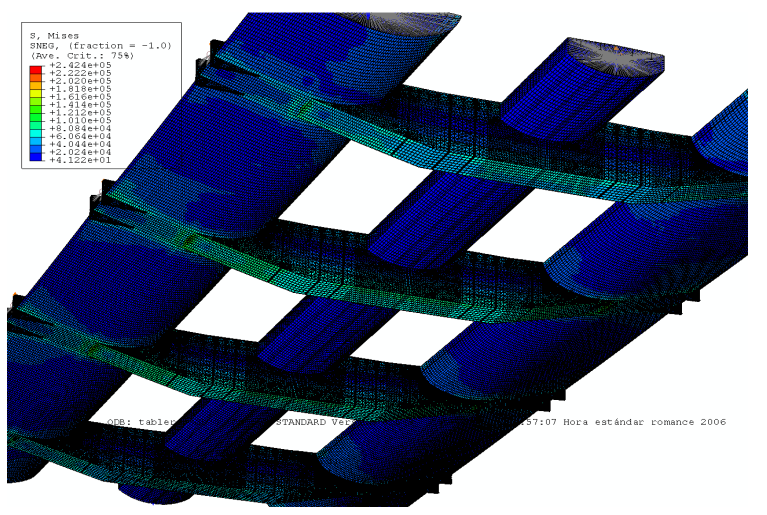

Figure 5: $\quad$ Local model of longitudinal girders and four transverse girders.

Due to the great dimensions of the bridge, the usual method of analysis in two steps: an initial linear step with dead loads and a second analysis including the effect of the geometric stiffness matrix calculated with the stress results obtained in the first step, produces a wrong vertical displacement in the middle of the span greater than $32 \mathrm{~m}$.

Subsequent nonlinear steps allow us to introduce static or seismic loads. The results of displacements, forces and stresses are used for global checks or as resultant global forces applied in local models to study in detail the behaviour of several parts including geometrical and material nonlinearity. Figure 5 shows a local model of girders section made of more than 500.000 shells elements, including all the internal stiffeners as shell elements. In the limits of the section, forces and moments obtained from the global model in the corresponding beam nodes are introduced at the center of gravity of girders by kinematics coupling conditions, and were distributed over the section girder nodes. In the same manner, hanger forces and loads that affect to the modelled shell elements are 
considered to achieve the equilibrium in a fully nonlinear analysis, allowing us to study in detail the plastic behaviour and local buckling effects.

In the case of the towers, the Messina tower was first modelled with a local model (figure 6a) using 3D beam elements, and springs representing the foundation stiffness in the bottom nodes and springs in the top connection with the main cables calculated from the global model (figure 6b) applying several levels of horizontal, transversal and vertical loads at the top of the tower.

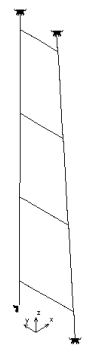

(a)

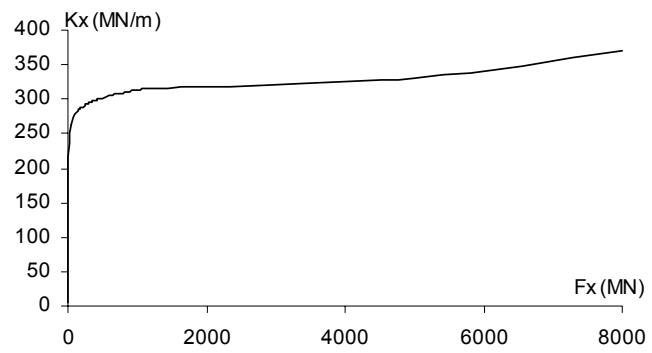

(b)

Figure 6: Local beam model of the Messina tower (a); and longitudinal behaviour for the top springs that model the connection with the suspension cables (b).

Then a complex shell model of half tower, with more than 80.000 shell elements (figure 7), was developed to analyze the plastic behaviour, possible local buckling and the push-over study. In this model, springs in top and bottom planes are included at the center of gravity of each section, by distributing couplings modelling a master central node connected with the spring and several slave nodes in the shell section. External loads are applied in a similar way using kinematics linear couplings.

\section{Seismic loads}

The design seismic motion is defined by the response spectra of the horizontal (figure 8 ) and vertical components, considering a modal damping ratio of 5\%, and with four levels of the peak acceleration shown in table 1, with the associated return period and the probability of not exceeding them during the life of the structure of 200 years.

For the nonlinear dynamic analysis, the Northridge 1994 N-S (figure 9) and E-W earthquake components were initially used. A comparison of the pseudoacceleration response spectra of this earthquake and the correspondent design spectra for the ULS state is presented in the same figure.

Using the program Simqke [5] a set of artificial quakes adjusted with each of the pseudo-acceleration design spectrums with low tolerances were developed. Figure 10 shows one artificial earthquake named "71" that adjust on the security side of the design PSA spectra for the ULS state. 
These earthquakes were applied first as uniform base excitation imposing their accelerations at all nodes connected with terrain. After that, the possibility of non-uniform support movement [6] was analyzed imposing different quake displacements in each support, using the same earthquake but with temporal translations as a function of the Vs waves velocities.

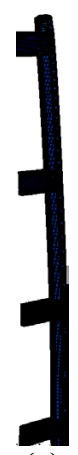

(a)

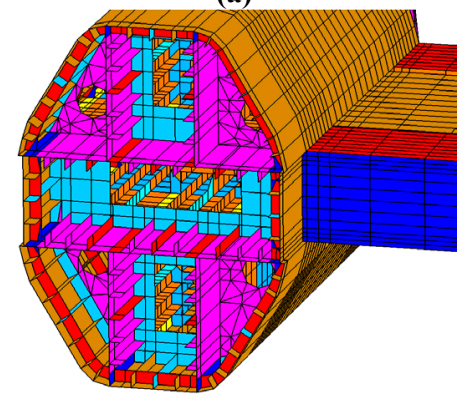

(c)

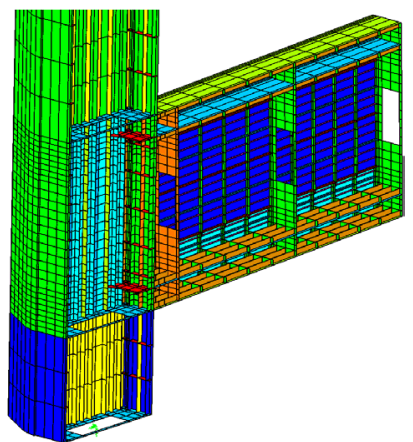

(b)

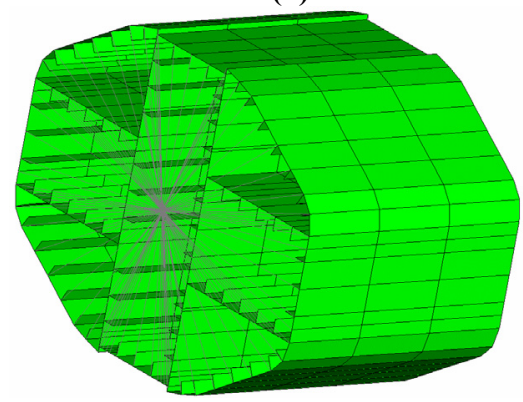

(d)

Figure 7: (a) Messina tower local shell model; (b) Section detail of one connection; (c) Column stiffeners; (d) Kinematics couplings for load application.

Table 1: $\quad$ Peak ground acceleration levels in each load condition.

\begin{tabular}{|c|c|c|c|c|}
\cline { 2 - 5 } \multicolumn{1}{c|}{} & SLS1 & SLS2 & ULS & SILS \\
\hline Peak ground acceleration $\left(\mathrm{m} / \mathrm{s}^{2}\right)$ & 1.2 & 2.6 & 5.7 & 6.3 \\
\hline Return Period (years) & 50 & 200 & 2000 & 10000 \\
\hline$\%$ Probability of not exceeding & 1.8 & 37 & 90 & 98 \\
\hline
\end{tabular}

\section{Vibration modes}

Considering the global bridge model, table 2 shows the first six modes calculated by different analysis. In the case of column named "nonlinear", modes $(\Phi)$ and frequencies $(\omega)$ are calculated using the full nonlinear stiffness matrix $\left(K_{\mathrm{NL}}\right)$ obtained from an initial nonlinear static step with dead loads: 


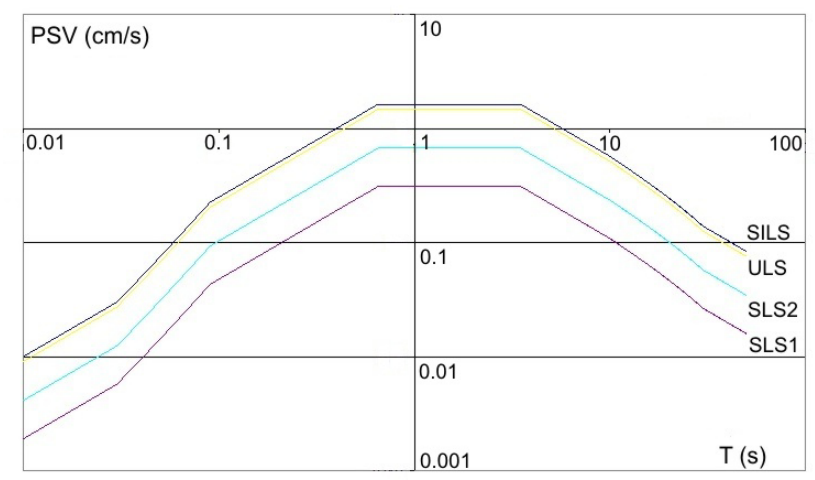

Figure 8: $\quad$ Pseudo-velocity spectrums.

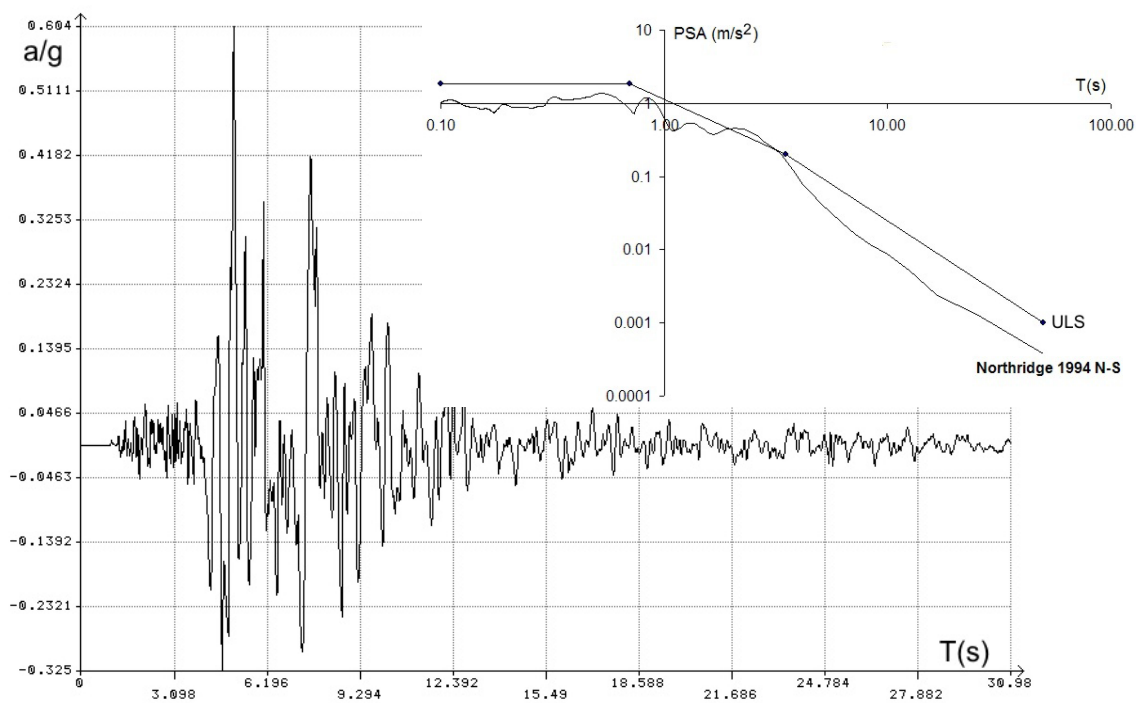

Figure 9: $\quad$ Northridge (1994) N-S time history quake and PSA spectra.

$$
\begin{aligned}
& \left(K_{N L}-\omega^{2} M\right) \Phi=0 \\
& K_{N L}=K_{L}+K_{\sigma}+K_{G}
\end{aligned}
$$

where $\boldsymbol{K}_{\mathrm{L}}$ is the linear stiffness matrix, $\boldsymbol{K}_{\boldsymbol{\sigma}}$ is the geometric stiffness due to initial stresses, $\boldsymbol{K}_{\mathbf{G}}$ is the nonlinear stiffness due to node displacements, and $\mathbf{M}$ is the lumped mass matrix.

Values in the column named "live loads" are calculated with the full $\boldsymbol{K}_{\mathbf{N L}}$, obtained form a second step that adds to the initial dead loads the loads due to four centered trains with $750 \mathrm{~m}$ of length. The variations of vibration modes are significant but less than $10 \%$ of the previous values. Finally, in the column 
"Only $\mathrm{K}_{\sigma}$ ", vibration periods calculated using only the geometric stiffness matrix from dead loads are shown. The variations in modes are less than $5 \%$ of the initial values, although the modes 5 and 6 change their positions.

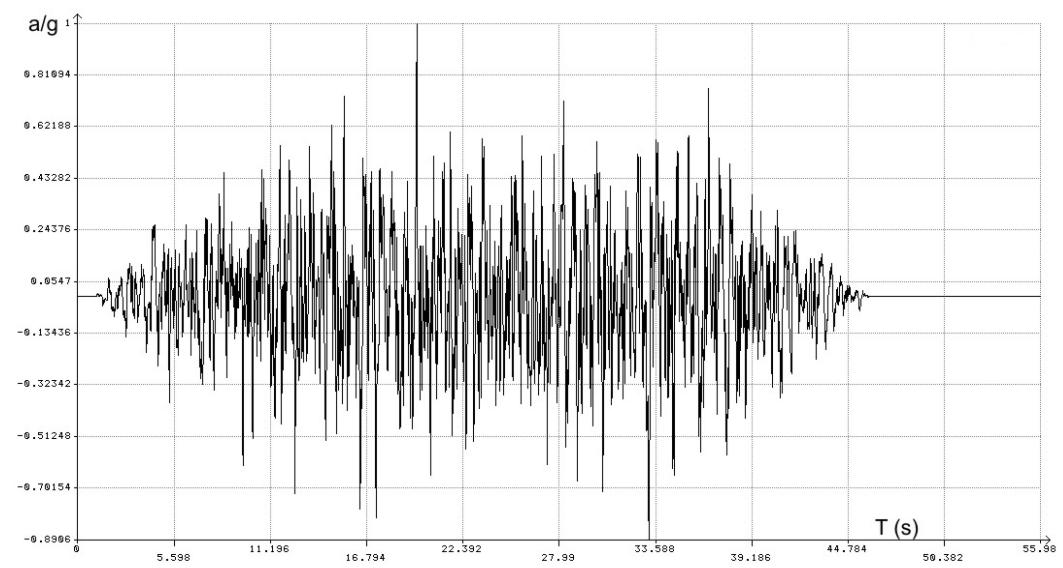

Figure 10: Artificial earthquake 71 time history and PSA spectra.

Table 2: $\quad$ First six vibration periods (s) of bridge global model with different analysis.

\begin{tabular}{|c|c|c|c|c|}
\hline Mode & Nonlinear & Only $\mathrm{K}_{\sigma}$ & Live loads & Description \\
\hline 1 & 31.98 & 32.18 & 32.81 & First horizontal symmetrical \\
\hline 2 & 17.48 & 17.57 & 19.21 & First horizontal anti-symmetrical \\
\hline 3 & 16.54 & 16.55 & 17.31 & First vertical anti-symmetrical \\
\hline 4 & 12.28 & 12.10 & 12.62 & First vertical symmetrical \\
\hline 5 & 12.01 & 12.31 & 12.32 & First torsional anti-symmetrical \\
\hline 6 & 11.95 & 12.02 & 11.51 & Second horizontal symmetrical \\
\hline
\end{tabular}

In the case of local Messina tower model of figure $6 \mathrm{a}$, the first transversal $\left(\mathrm{T}_{1}\right.$ $=3.26 \mathrm{~s})$ and longitudinal $\left(\mathrm{T}_{2}=2.97 \mathrm{~s}\right)$ modes, obtained in the nonlinear method are shown in figure 11, next to the first mode of the global model. To achieve these periods about $3 \mathrm{~s}$. in the global model, more than 50 modes must be calculated due to the great number of vibration modes involving main cable vibrations that appear. For that reason, to reach mass participating factors over the $90 \%$ in each spatial direction, a great number of modes (more than 100) must be considered in the global model.

\section{Dynamic nonlinear analyses}

Due to the geometrically nonlinear behavior, all the global seismic analyses were done by direct integration of coupled dynamic equilibrium equations using 
Newark's method with average acceleration integration $(\gamma=0.5, \beta=0.25)$, to achieve stability unconditionally.

Rayleigh damping was considered by adjusting modal damping of several pairs of modes to check its influence in the results. Figure 12 shows the pairs of modes used. Finally the modes 1 and 166 were used $\left(T_{1}=31.98 \mathrm{~s}, T_{166}=1.11 \mathrm{~s}\right)$ with a damping coefficient for stiffness matrix of 0.045 , and 0.017 for mass matrix.

Seismic analysis was carried out in two steps; the first to apply dead and live loads and then the earthquake load was applied with the response integrated with time steps of $0.02 \mathrm{~s}$. Considering the artificial earthquake of figure 10, applied in longitudinal and transversal direction, figure 13 shows several nodal time history displacements, and figure 14 shows the variation of longitudinal moment and axial force in one column of the Messina tower for the ultimate limit state ULS71, calculated with the envelope of seismic results.

$$
\mathrm{ULS71}=1.15 \mathrm{PP}+1.5 \mathrm{PN}+1 \mathrm{IMP}+1.1 \mathrm{QA}+1 \mathrm{VS}+1 \mathrm{VT}
$$

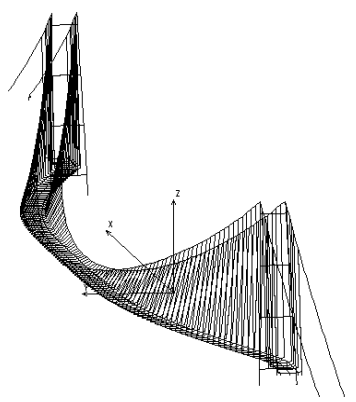

$\mathrm{T}=31.98 \mathrm{~s}$

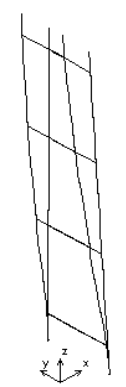

$\mathrm{T}=3.26 \mathrm{~s}$

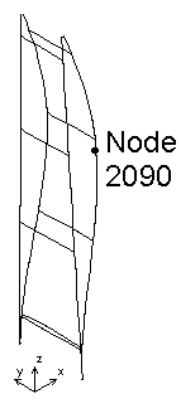

$\mathrm{T}=2.97 \mathrm{~s}$

Figure 11: Vibration modes in global and local models.

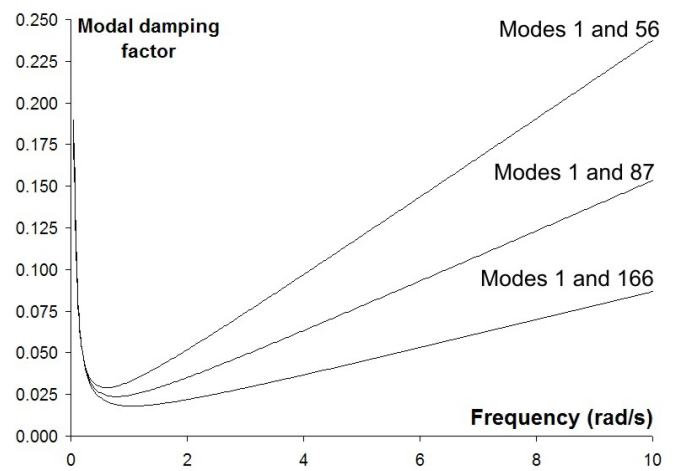

Figure 12: Rayleigh damping curves. 


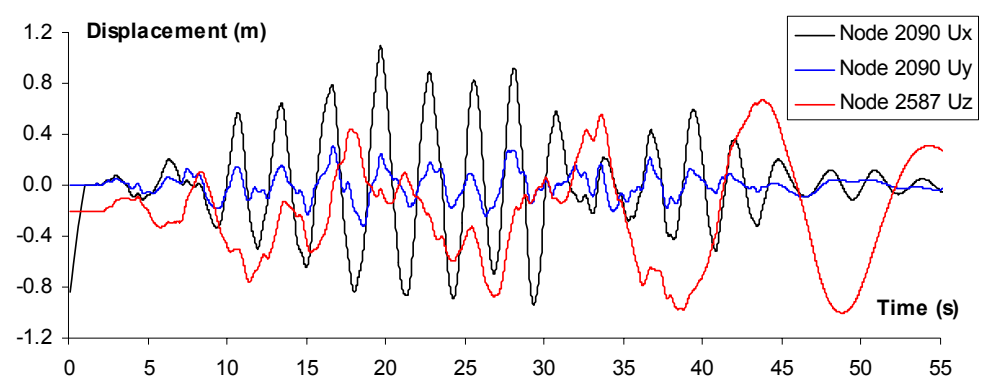

Figure 13: Time history of nodal displacements.

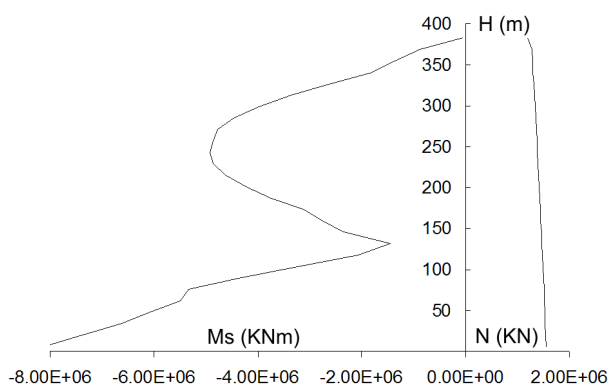

Figure 14: Longitudinal moment and axial load in Messina tower shaft for ULS 71.

Tower maximum displacements in longitudinal direction are about $1.1 \mathrm{~m}$ (see position of node 2090 in figure 11). Transversal earthquake displacements in towers are smaller, with maximum values about $0.5 \mathrm{~m}$, located in the upper part. In the central position of the bridge (node 2587 in figure 13), maximum seismic displacements are smaller in comparison with the rest of loads, with maximum values of $0.42 \mathrm{~m}$. in longitudinal direction, $1.29 \mathrm{~m}$. in transversal direction, and $1 \mathrm{~m}$ in vertical displacements.

\section{Messina tower longitudinal push-over analysis}

A nonlinear static analysis including geometrical and material nonlinearities was carried out using the local shell model of Messina tower shown in figure 6. The aim of the push-over analysis is to determine, statically, the resistant capacity, ductility, collapse mechanism and security level of the structure, without performing complex nonlinear seismic analysis [7, 8]. The ultimate state considered was: ULS71 = 1.15PP + 1.5PN + 1IMP + 1.1QA + LF x VS+1VT.

In the first nonlinear stage all loads except the seismic ones were applied, and in the second step seismic load was applied proportionally until collapse. Several methods have been proposed to generate the equivalent seismic load pattern in the push-over analysis [9]. In our case, since the longitudinal seismic response of the tower is determined by the second local mode of vibration $\phi_{2}(\mathrm{~T}=2.97 \mathrm{~s}$ in 
figure 11), the load pattern $\left(P_{\mathrm{s}}\right)$ used (figure 15a) was calculated using the tower masses associated to dead loads $(m)$ in each section with:

$$
P_{s}=\lambda m g \phi_{2}
$$

where the load factor $\lambda$ was calculated in a way that the static application of load $P$ s gives a base moment equal to the maximum obtained with the correspondent seismic time history analysis.

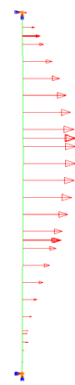

(a)

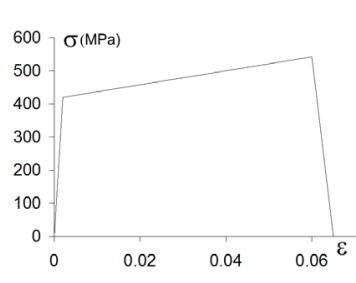

(b)

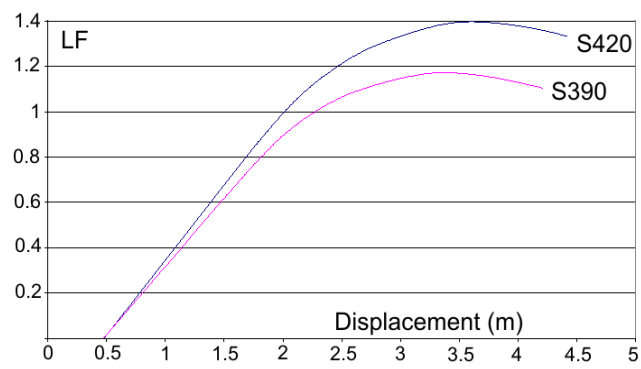

(c)

Figure 15: (a) Seismic load pattern; (b) Stress-strain curve for steel S420; (c) Longitudinal pushover results.

Steel types S390 and S420 were considered in the analysis, using stress-strain diagrams like the one shown in figure $15 \mathrm{~b}$ for the S420, with an elastic modulus $\mathrm{E}$ of $2.1 \times 10^{8} \mathrm{KPa}$, initial plastic deformation of $0.2 \%$, elasticity tangent modulus of $\mathrm{E} / 100$ and ultimate deformation of $6 \%$.

In stage 1, without seismic loads, maximum displacements are $1.18 \mathrm{~m}$ in tower head, and $0.48 \mathrm{~m}$ in node 2090 (see position in figure 11); the entire tower was in elastic state. Figure $15 \mathrm{c}$ shows the longitudinal displacements obtained in node 2090 during the second nonlinear stage with linear increments in the load factor LF that multiplies the equivalent static load Ps. With S390 steel, plastic behavior starts for $\mathrm{LF}=0.94$, and the collapse load factor takes place for $\mathrm{LF}=$ 1.17 and a longitudinal displacement of $3.4 \mathrm{~m}$ in node 2090. Using the S420 steel, global ductility grows and the maximum load factor is about 1.4.

\section{Conclusions}

- Several seismic preliminary checks of the initial design project of the Messina Bridge have been presented.

- The use of simplified global models with beam and springs elements allows to perform geometrically nonlinear static and seismic time history analysis.

- Results obtained from global models are transferred to detailed shell local models, which allowed us to rerun analysis including geometrical nonlinearities and non-linear materials. These local models, combined with normative checks, help us to understand the structural behaviour under collapse and the position and problems of critical areas. 
- Several analysis must be improved, such as including material nonlinearities in the global beam bridge model, seismic effects of tuned mass dampers located in towers, and consideration of residual stresses and local imperfections in local shell models.

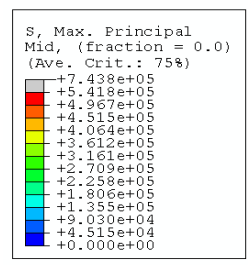

(a)

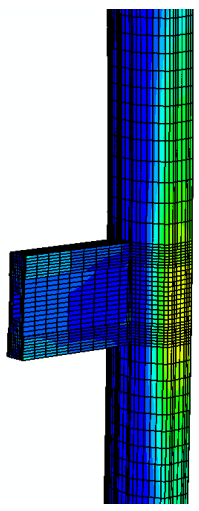

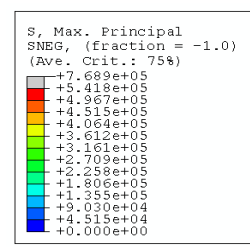

(b)

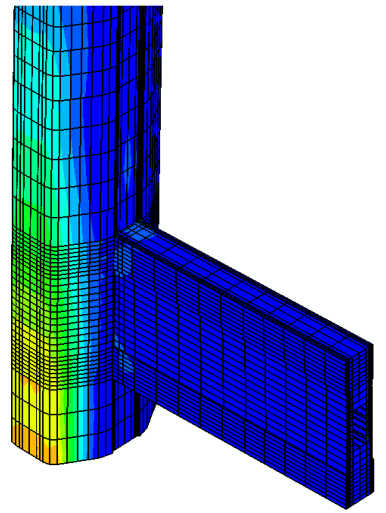

Figure 16: Maximum principal stresses previous to the collapse in the proximities of node 2090 (a), and in the base tower (b).

\section{References}

[1] Cosmos/m v.2.9. Finite Element Analysis System: I) User Guide, IV) Advanced Modules. Structural Research \& Analysis Corp., (2004).

[2] Abaqus, I., (ed.) Abaqus 6.5. Standard Uses Manual. Pawtucket, Rhode Island, 2004.

[3] Bathe, K.J., Finite Element Procedures. Prentice Hall: Englewood Cliffs, N.J., 1996.

[4] Crisfield, M.A., Non-Linear Finite Element Analysis of Solids and Structures. Vol. 2: Advanced Topics. John Wiley \& Sons: Chichester, 2001.

[5] SIMQKE, A Program for Artificial Motion Generation. NISEE/Computer Applications (1986).

[6] Chopra A.K., Dynamic of Structures. Theory and Applications to Earthquake Engineering. Pearson Prentice Hall: New Jersey (2007).

[7] Lu, Z., Ge, H. \& Usami, T., Applicability of Push-over Analysis Based Seismic Performance Evaluation Procedure for Steel Arch Bridges. Engineering Structures 26 (2004).

[8] Archer, G.C., A Constant Displacement Iteration Algorithm for Nonlinear Static Push-Over Analyses. Electronic Journal of Structural Engineering, 2 (2001).

[9] Endo, T.K., Chihiro, K., Shigeki, U., Analytical Study on Seismic Performance Evaluation of Long-Span Suspension Bridge Steel Tower. $13^{\text {th }}$ World Conference on Earthquake Engineering, Vancouver. Canada (2004). 